\title{
The Role of Community-Based Media in Strengthening, Preserving, and Promoting Identity and Culture: A Case Study in Eastern Thailand
}

\author{
By Pisapat Youkongpun*
}

The purpose of this thesis is to investigate and analyse the role of community-based media in information distribution in the Riverside community, Chanthaburi province, Eastern Thailand. Recently, this strong community has been identified as a cultural tourism destination. The community has started to produce its own media, and to use social networks to promote itself and its attractions to the nation. This project advances knowledge of the role of community-based media in a community environment in the Thai public sphere. Furthermore, it strengthens knowledge of the role of community-based media in its broadest sense as an important form of cultural production. By using ethnographic action research, this research gains strength through a rich understanding of the community by following an ongoing research cycle of planning, doing, observing and reflecting. Beyond that, this study reflects the idea of "hyperlocal" media. With approximately a hundred households on which to focus, it is much easier for hyperlocal media to reach local people by providing local news, covering local politics and engaging local people in the affairs relevant to their area. As a result, the findings of this paper will reinforce the idea that "hyperlocal" communication has played a much more proactive role in the community context.

Keywords: community-based media, hyperlocal and community, Thailand

\section{Introduction}

This research will focus on the idea of multiple public spheres where locals have the ability to intensify their participation by creating alternative spaces in which they are able to speak in their own voices and express their cultures and identities using their own idioms and styles (Fraser, 1990). The Riverside community is one local community in Thailand which produces its own media to serve the community members' needs, especially that of cultural preservation which is critical for the local tourism industry. With the aim of advancing knowledge of the role of community-based media in this community, it is essential to know how media discursive activities can unite and strengthen each member in this community. With more than a hundred households in the community, each local communication medium, in other words, each community-based media plays a significant role in creating, sustaining and promoting a strong community. Through the age of digital technology, "hyperlocal" or "space of community" matters on the internet have

\footnotetext{
${ }^{*}$ Student Researcher, School of Humanities, Griffith University, Australia.
} 
been much more influential towards the local community sector in every part of South-East Asian countries, including Thailand.

\section{Methodology}

A case study approach was chosen in this project in order to observe the media activities in a community. This approach was adopted because it is a unit of human activity in the real world (Bill, 2010). A small and single case study of the community centered on the Riverside community -a popular cultural tourism destination- in Chanthaburi, Eastern Thailand. This community is about 300 years old. There are approximately one hundred households. Historically, it was a trading point. Thais normally farmed the land while the Chinese and Vietnamese inhabitants were traders and merchants. This is why nowadays, people can see a multicultural mix of Thais, Chinese and Vietnamese in the community. In 2009, the community was chosen by Chanthaburi's Office of Commerce to be a new cultural tourism destination in Thailand. As a result, community members have started producing their own media to promote their community and themselves to the nation.

A key element of my methodology is ethnographic action research or EAR. EAR was designed to discover the benefits of ethnography in the development of a transferable methodology for monitoring and analyzing media and communication for development initiatives (Tacchi, Foth \& Hearn, 2009). In order to understand this research plan, I will examine the two key components of this research tool: ethnography and action research.

Ethnography is a scientific approach to investigating social and cultural patterns and meaning in communities, institutions, and other social settings (Schensul, Schensul \& LeCompte, 1999). Ethnography is designed to document the culture, and the practices of the people in these settings. The aim is to analyze how each group of people sees the world (Reeves, Slater \& Hearn, 2008). Tacchi, Kuper and Hodges (2003) also state that ethnography is based on long-term engagement with the field of study which the researchers can truly understand, interpret and analyze the subject of the study.

Ethnography can be fit with action research because it is the way to understand the particular community and the project work simultaneously. Action research, or sometimes called participatory action research, is used to improve practices, and it involves action, evaluation, critical reflection which is based on the gathered evidence, and changes in practice (Koshy, Koshy \& Waterman, 2011). As Streubert and Carpenter (2002) assert, this type of qualitative research is to seek action to improve practice and to study the effects of the action that was taken. The features of the action research involve a spiral of self-reflective cycles (Figure 1). 
Figure 1. Action Research Spiral

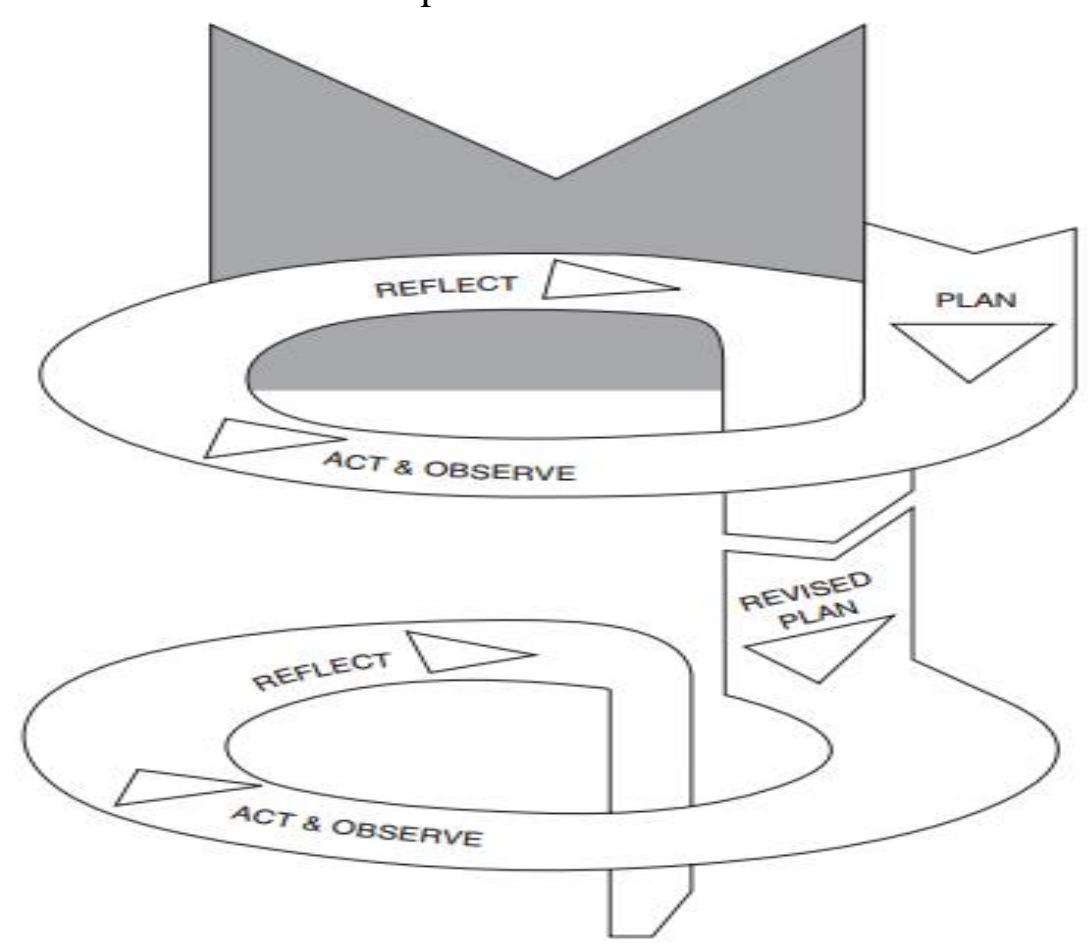

Source: Kemmis and McTaggart, 2005.

Kemmis and McTaggart (2005) also demonstrate in this figure that real practice might not be neat as this spiral containing planning, acting, observing, and reflecting suggests. These stages will overlap, and initial plans will become obsolete in the light of learning from experience. In fact, the process is likely to be more fluid, open, and responsive. Furthermore, the success of this action plan does not depend on the faithfully following these steps, but is achievable through a strong sense of evolution and development in the researcher's practices and understandings.

In other words, EAR is a research method which integrates ethnography presenting a culture - into the action research plan - developing a project. EAR is an approach that can be employed to develop the project through a rich understanding of the community.

The research method includes media observation, interviews with key people and surveys of audiences designed to enable exploration of the research questions. The research is designed to fit as much as possible into the everyday flow of village life to ensure maximum participation with minimum disruption. This flexibility will encourage community members to speak freely about their views on community media and its impact on their lives. 


\section{Media and the Public Sphere}

\section{The Notion of the Public Sphere}

This study will utilize the notion of the public sphere based on the work of Habermas (1989) and others (Calhoun, 1992; Fraser, 1990). The concept of the public sphere was originally elaborated in the book, The Structural Transformation of the Public Sphere, in 1962 by Jurgen Habermas, a German sociologist and philosopher in the tradition of critical theory and pragmatism. Habermas' theory of the bourgeois public sphere is part of Enlightenment, liberal political philosophy which addresses the question of what can make democracy works. The public sphere is an arena where individuals come together and freely discuss ideas which influence political action. As Habermas (1989) argues, capitalism requires a public space where information can be freely exchanged. Not only information about business but also culture and politics might be freely discussed (Habermas, 1989). In evolving public sphere institutions such as salons and coffee house, he argued that conversation took place among equals whose private interests and inequalities were suspended. As a result, it allowed for rational discussion and debate on questions of state action and policy. Habermas (1989, p. 49) asserts:

By "the public sphere" we mean first of all a realm of our social life in which something approaching public opinion can be formed. Access is guaranteed to all citizens. A portion of the public sphere comes into being in every conversation in which private individuals assemble to form a public body. They then behave neither like business or professional people transacting private affairs, nor like members of a constitutional order subject to the legal constraints of a state bureaucracy. Citizens behave as a public body when they confer in an unrestricted fashion, that is, with the guarantee of freedom of assembly and association and the freedom to express and publish their opinions, about matters of general interest.

As time passes, rapid social changes, social developments, literacy growth and industrialization have decreased the importance of his particular construction of the public sphere, thereby challenging its relevance. A clear distinction between public and private, identified by Habermas, is no longer exists. Dahlgren (1991, p. 4) argues that "a blurring of the distinction between public and private in political and economic affairs, a rationalization and shrinking of the private intimate sphere (family life) and the gradual shift from an (albeit limited) public of political and cultural debaters to a public of mass". Furthermore, there is no equality; reason is not the main and necessary basis for discussion and debate and all citizens cannot be guaranteed access to the public sphere anymore (Butsch, 2009). As a result, the ideas of multiple public spheres have been introduced by many critics.

One of the most influential criticisms of Habermas' theory of the public sphere comes from Nancy Fraser, an American critical theorist. Her work, 
Rethinking the public sphere: a contribution to the critique of actually existing democracy, was firstly published in 1992 after the publication of the Structural transformation in English. From Fraser's point of view, the concept of the public sphere is not adequate for the current forms of democracy which exist in late capitalist societies. She does not agree with the four dimensions proposed by Habermas and identifies inequalities that continually operate in democratic societies (Fraser, 1990). She points out the absence of subordinate groups, including women and lower classes in bourgeois public sphere institutions (Calhoun, 1992). The "absence of reference to the complexities and contradictions of meaning productions" is used to describe Habermas's idealization of the bourgeois public sphere (Dahlgren, 1991).

Fraser (1990) considers that the idea of a multiplicity of publics is much more preferable to the concept of a single public sphere with each sphere likely to overlap to some extent. She argues that individuals have moved away from the universalizing ideal of a single public and participate in other spheres or overlapping public discourses. The move away from the ideal of a single public sphere is important in that it allows recognition of the public struggles and political innovations of marginalized groups outside traditional or statesanctioned public spaces and mainstream discourses dominated by white, bourgeois males (Squires, 2002). A single public sphere does not provide a space for subordinated groups in which they can discuss their own ideas and assumptions about the world. Minority group members have repeatedly found it advantageous to constitute alternative publics, or subaltern counterpublics, in recognition of the impossibility of keeping societal inequalities out of the public sphere process. Fraser (1990, p. 66) asserts that "they (subordinated groups) would have no venues in which to undertake communicative processes that were not, as it were, under the supervision of dominant groups". Multiple public spheres have the ability to intensify their participation by creating alternative spaces in which people are able to speak in their own voices and to express their cultures and identities using their own idioms and styles.

\section{Community Media in the Public Sphere}

Habermas's notion of the public sphere should be reconceptualised. Instead of adopting the ideal single public sphere, the term of parallel and overlapping public spheres - multiple public spheres - should be more focused. The activity called "across lines cultural diversity" (Fraser, 1990, p. 13) emerges when people articulate their own discursive styles and formulate their positions on issues which are later brought out from their preferable minor spheres to a wider public sphere. As a result, Meadows, Forde, Ewart and Foxwell (2007, p. 68) point out, "what we might term, a 'community public sphere' can be seen as a discrete formation or space that develops in a unique context and as a product of contestation with the main public sphere". In other words, the multiple public spheres are deeply represented by community-based media. It facilitates various community public spheres which might be defined as a process of cultural empowerment. As a result, it is resource for building 
multiple and complex media and cultural literacies through participation on a localised and personalised scale (Meadows et al., 2007).

There are four essential characteristics of community-based media localism, storytelling, empowerment and diverse participation. The first characteristic is localism. Community media is created primarily with and by people of a specific geographic place. Johnson and Menichelli (2007) assert that community media helps define the places where people live and how they relate to one another, and also reflect local values and cultures. Community broadcasting in Asian countries such as Thailand is also responsible to local needs. For example, there is an observation of community radio contents in Chiang Mai, Northern Thailand. It shows that the most popular content is relevant to local news and music which is followed by the content about local wisdom. When compared by Thai regions, community radio broadcastings in the West, the Central Plains and the South usually broadcast local news, while radios in the Northeastern Thailand preferably focus on local wisdom (Wellmanee, 2008).

Storytelling is another characteristic. "Storytelling is the oldest form of education. People around the world have always told tales as a way passing down their cultural beliefs, traditions, and history to future generations, Why? Stories are at the core of all that makes us human"' (Hamilton \& Weiss, 2005, p. 1). Community members are uniting with the community history and culture by those stories. Community media is a channel for it. It allows the members to tell their story and experience. Community media has the ability in reducing isolation and alienation by allowing people to tell their stories to others, as Johnson and his colleague (2007) point out, the stories can start a deliberative process among community members and unite them together.

The third one is empowerment. The core idea of the concept of empowerment is power. Lips (1991) defines power as control or influence, often treating power as a commodity or structure divorced from human action. The foundation of empowerment is based on the idea that power can change and even be extended. Community media is a process of giving power to the individuals as Hamilton and Weiss (2005) say, it aims to put communication tools in the hands of individuals, to share access with non-professionals, and to support self-expression and community building. Community media empowers people by providing a voice to the voiceless.

Community media increases the community participation level in which public expression is the main concern. The final and the most important element of community-based media is diverse participation. Community media is responsible for the inclusion of diverse voices within the community, and community participation is emphasized by its distribution and production processes (Johnson \& Menichelli, 2007, p. 3). The examples are Muslim radio stations in New York, Thai radio programs in Brisbane and Chinese community radio in Thailand. These community media serve and embrace their audiences, create in collaboration with the community they live, and make reconciliation and understanding between people in the community and the outside world, as Meadows and his colleagues (2007, p. 71) state, "the 
instances of 'micro-participation' enabled by community media contribute to a broader 'macro-participation' as participants actively adopt civic attitudes and actions and perform a pivotal role in a healthy democracy".

\section{New Media and "Hyperlocal"}

The new today is old tomorrow. At the time was the internet was not invented. In people's perception, new media was broadcasting - radio and television. Radio, the first medium for broadcast journalism, was the starting point for people to communicate to the masses. Then, television was exciting and persuading by bringing both audio and visual elements to the public audiences. However, there was critical concern about the survival of authentic cultures in the era of breakthrough broadcasting technology such as the internet. Broadcasting media were feared as tools of political propaganda and suspected of being able to weaken the fabric of society and to ruin cultural heritage (Jankowski, 2002). There was research into developing countries about the role of broadcasting in cultural continuity conducted by Katz (1977). The big question was whether or not authentic cultures can survive new media. The outcome of this research was surprising. Instead of being shaped by the media, the cultures shaped media to their own purpose as demonstrated in Mexico and Thailand. In Mexico, the 30 or 60 minute telenova, the most popular television program, and originally, an American soap-opera, was adapted to the Mexican historical drama telling the story of Mexico's march to independence. Although there was a decline in a proportion of indigenous creativity and performance in Thailand, the Mau lum folk opera and the griot singing of lineages and history as chroniclers of an oral tradition were successfully incorporated into broadcasting through radio and television in that period (Katz, 1977).

New media is believed to be a tool to help rediscover and reinvigorate each community. Rheingold (2000) points out that the loss of traditional cultures and values can be regained via communication among people in the internet. Faye Ginsberg discusses the ways by which the minority groups, the Inuit people of the Arctic, re-create oral traditions via digital media like video and film thereby empowering ethnic and indigenous communities (Ginsburg, Abu-Lughod \& Larkin, 2002). The means by which each Inuit filmmaker has created films as a response to dominant objectified representations show that:

Rather than destroying Inuit cultures as some predicted would happen, these technologies of representation -beginning with the satellite television transmission to Inuit communities of their own small-scale video productionshave played a dynamic and even revitalizing role for Inuit and other First Nations people, as a self-conscious means of cultural preservation and production and a form of political mobilization... . The benefit of new media is apparent not only in the narrative constructions of Inuit history on their own term, but in integrating it with Canadian modernity, embodied in the flow of television. (Ginsburg et al., 2002, p. 41-42) 


\section{Hyperlocal: An Online Local Voice}

Arguably, hyperlocal journalism focuses on the stories and articles which larger mainstream media organizations avoid. It serves the interests of community-wide and regional audiences. Hyperlocal media have much in common with community media. They both focus on even smaller geographic areas than national media. Nevertheless, most hyperlocal media tend to be online. One of the most interesting definitions of hyperlocal media is provided by Howley $(2009$, p. 2):

Hyperlocal implies something beyond the traditional confines of "community media", defined as a range of community-based activities intended to supplement, challenge, or change the operating principles, structures, financing, and cultural forms and practices associated with dominant media.

With a small area on which to focus, it is much easier for hyperlocal media to reach and attract local people by providing local news, cover local politics and engage local people in the affairs relevant to their area. Kurpius, Metzgar and Rowley (2011, p. 774) argue that hyperlocal media operations "are geographically-based... and intended to fill perceived gaps in coverage of an issue or region and to promote civic engagement". Hyperlocal sites can make engagement easier for some locals to deliver input when they cannot make it to a public meeting. It has also can lower the obstacles so that people can more easily launch community news sites on their own.

\section{Discursive Media Activities in the Riverside Community}

The Riverside community has been formed and shaped by communitybased media discursive activities. Theoretical elaboration on discourse is useful in identifying a variety of media discourses which are used at the local level. Discourse in this case, essentially allows for the inclusion of a complete range of media discourses - online services, social media, posters, bulletin boards, performances and even people themselves. Consequently, I will use the term media as discourse to include all manner of public communication used by members of this local community.

These media below characterize the essential characteristics of community-based media -localism, storytelling, empowerment and diverse participation. They definitely provide local information and issues which occur in this community. These media can reduce isolation among community residents and also empower people by allowing them to voice their opinion. 


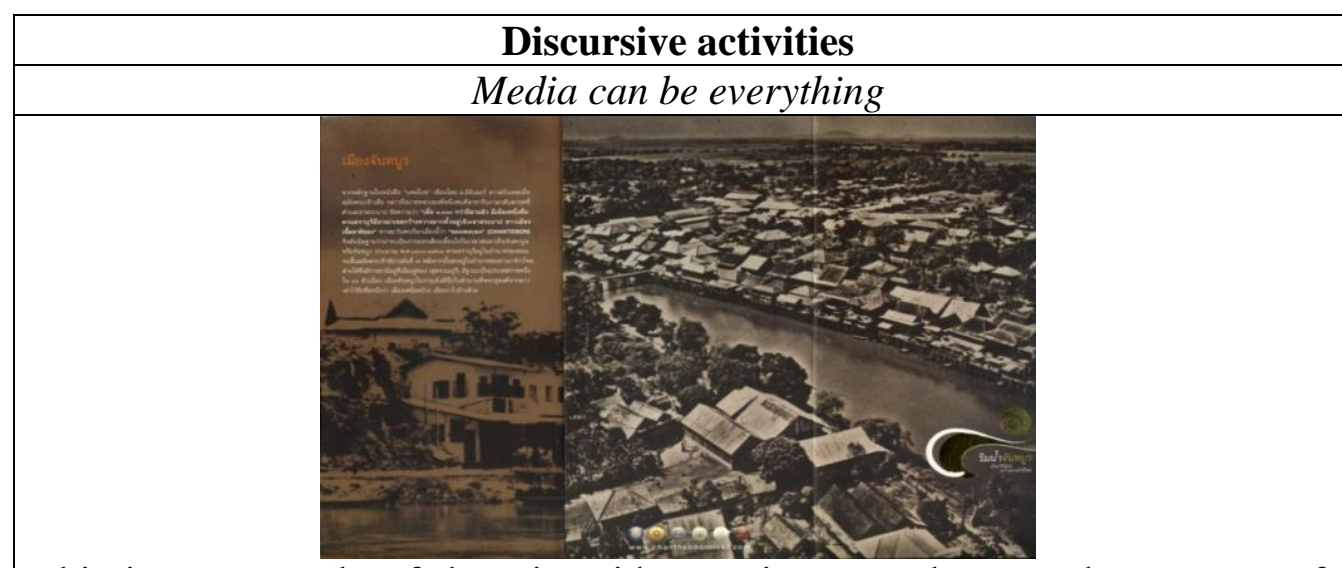

This is an example of the Riverside's Voices newsletters. The purpose of newsletters is to provide community member with the updated and valuable information of the community. They also included the community history and old architecture.

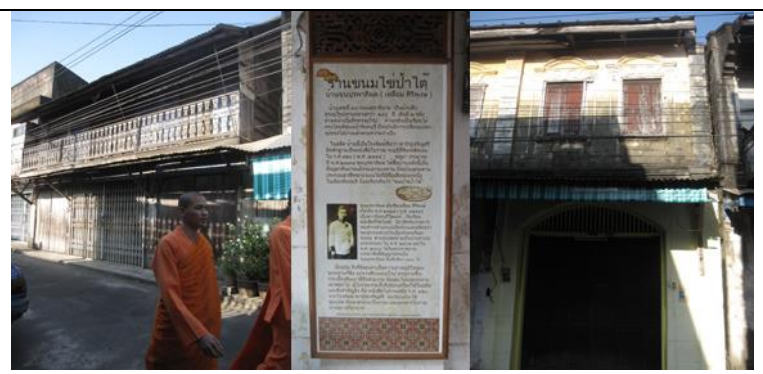

These are the information boards and posters through the community area that are used to present the historical background of each old building. The aim of these media is to promote historical sightseeing to the tourists.

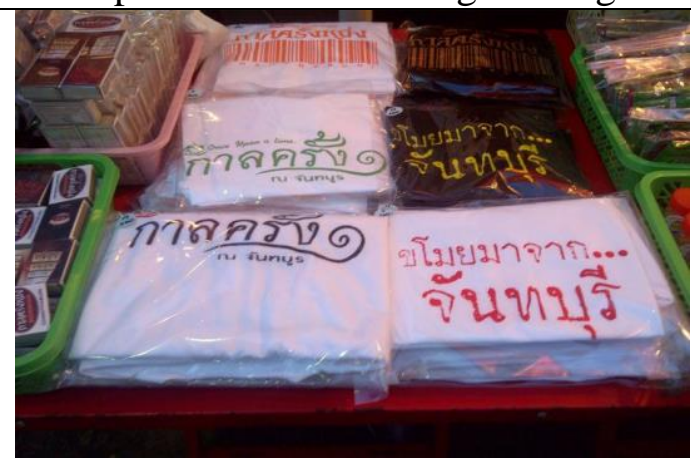

Screen-printed T-shirts are produced by the Riverside Community Development Association. It is one of the ways to promote the community, and also to improve the association's financial stability. 
The coffee place is located in the center of the community area. Most of the older people always spend their leisure time here with coffee, newspapers and Ska (traditional game similar to chess). It shows that Habermas's traditional public sphere such as the coffee house can still be found in the small community.

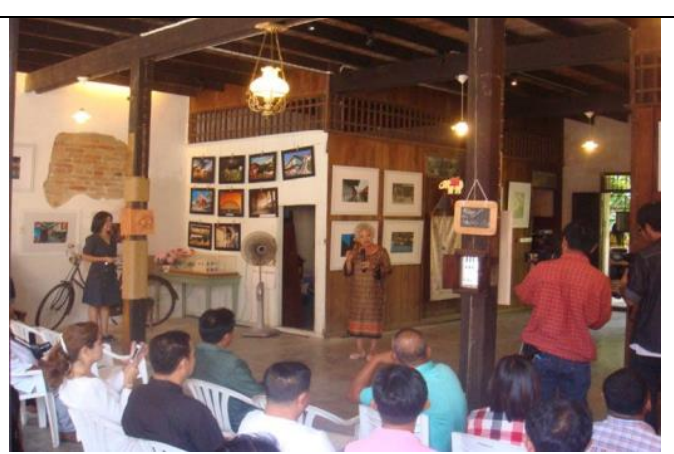

The community learning center is also located in the heart of community area. This house of learning is renovated with the aim of architectural preservation and community regeneration with sustainability. It is also the community meeting point where members come along and discuss community matters.

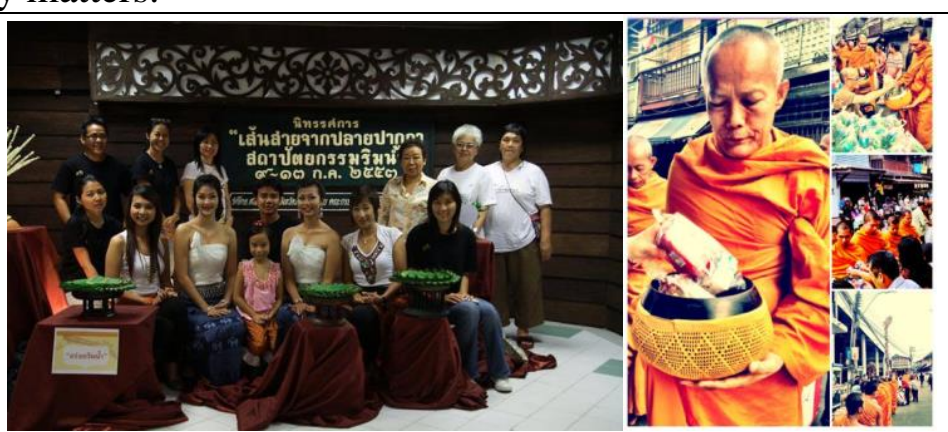

Community events including religious and commercial events are the other ways to strengthen community. Buddhist events are for uniting Buddhist members in the community. Most people move out of their houses into the street in order to provide food for the monks. Differently, the commercial events mainly aim to attract tourists from surrounding communities. The members sell street food and handmade products along the community street. 


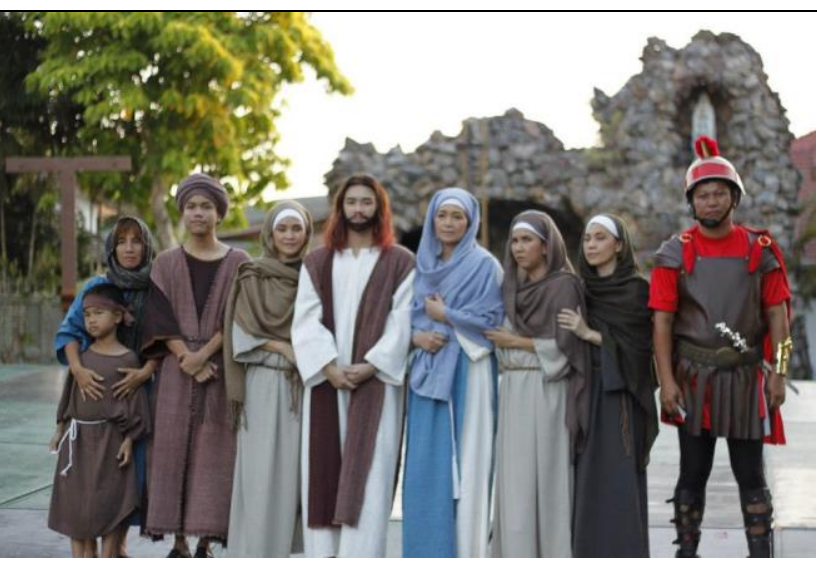

As the root of Vietnamese Catholicism, the religious performances are mainly conducted by the Catholic Church in the community. It is to strengthen Catholic people in the community. It also opens to the public to promote Catholic beliefs.

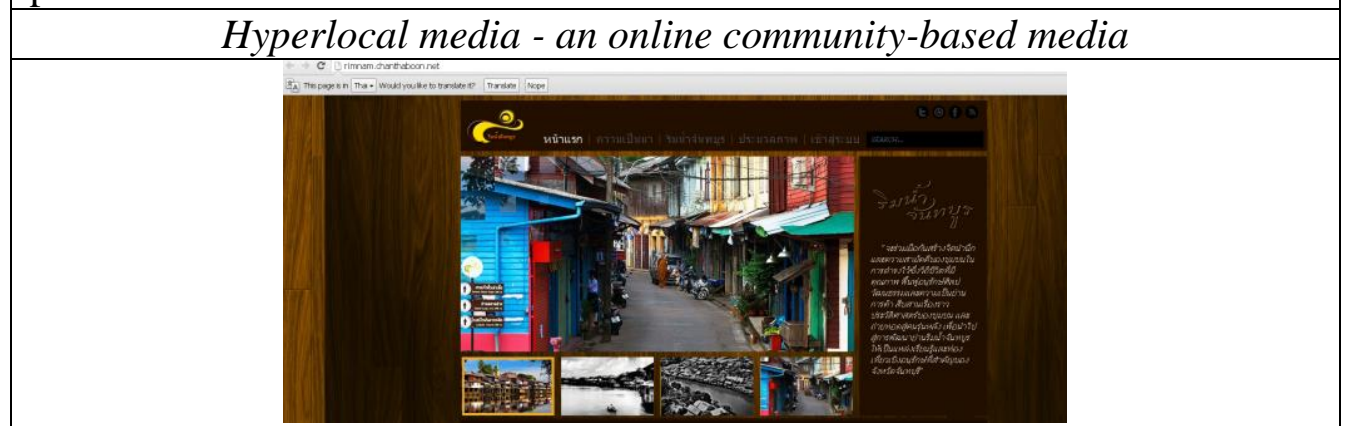

This is the official hyperlocal website for this community. There is updated information about events, attractions, interesting photos relevant to community activities, and the information of the Riverside Community Development Association.

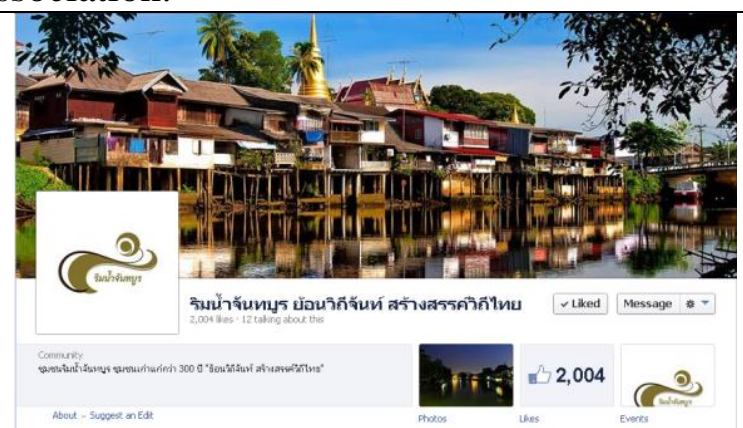

Facebook is the space for community members to receive and promote the information about each upcoming community event. Moreover, it is a forum for community member to discuss community problems such as neighbourhood noise and teenage alcohol consumption.

Source: The Riverside Community Photo Collection (The Chanthaboon Riverside Community Development Committee, 2012) 
There are a hundred participants were given a questionnaire exploring their use of community-based media. Thirty-four are male and 66 are female. The majority of participants are over the age of 50. Participants aged 36-50 years accounted for $24 \%$ while $12 \%$ are $26-35$ years, and only $5 \%$ are $18-25$ years.

Community-based media plays the most important role in the Riverside community as $62 \%$ of a hundred participants rely on their own media. Commercial media is second in importance while media supported by the government just partly support community information distribution. The result supports the idea that people have more ability to intensify their participation by creating their own media, so there are able to speak in their own voices and discuss about their own matters (Fraser, 1990).

People aged 18-35 have more frequent use of the internet. They use it for different purposes such as work-related matters, entertainment and social connections. Around $17 \%$ of the community internet responders say that they have participated online concerning community matters including participating in the community social media sites, responding to the chat room and also creating blogs about community issues. As one participant gives the reason of preferring online discussion, "when I attended the meeting, people might forget what I said. If I addressed something on the websites or Facebook, it would be there permanently".

There are several opinions on the role of community-based media in the community. Some are categorized as the followings.

1. Community-based media are informative. The media inform community members about the community meetings and events. Some of them such as information boards and signs in English language are also useful for many foreign visitors.

2. Community-based media preserve identity and culture. The high percentage of media content about community history, accounted for $77 \%$, shows how community members preserve their value and facilitate their identity and culture to others and the nation by using their own produced media.

3. Community-based media have a harmonising role. Community people feel like they are united by being informed community matters through the same media channels. As one participant says, "I feel so warm that people around me think that I am important enough to know what is going on in my community, and my opinion can make change to my community".

4. Community-based media promote tourism. Information about community attractions and tourism was sent from the community to the nation. An example is from a community Facebook activity.

We have just around a hundred households in the community, but we have got over a thousand of people following us on Facebook. There are not just us. It means people outside want to know about us ... want to know what is going on in the community. When we have got 
something like street events, we post it on Facebook. You see ... lots of people come to our community. Then, when those people come here, they take a picture and post it in on Facebook, so their friends know what is going on in our community. Now, you can guess what's next. Yes, lots of people come here. This is so much like a snowball game. (P. Chatmalai, President of Riverside Community Development Association, personal communication, August 28, 2014)

5. Community-based media are hyperlocal. Everything in the community can be news, and people can reach it online without getting out of their houses (Howley, 2009). As one participant says, "there was a wife run after her husband in front of my house. It was so funny that she tried to hit her husband with the wok. People shared this incident on the Facebook and community websites. It was such a talk of the town!".

\section{Conclusions}

This case study refers to the inclusion of all media activities produced locally, and are much effective in allowing community members to become empowered, to preserve cultural background, and to promote themselves to the external environment. The online activities have become more essential in serving the interests of community-wide and local audiences. Innovative hyperlocal media models, community-based media which tends to be online, are gathering increasing attention in this community and many parts of the world. It deepens the meaning of a place and to deliver a range of new and better local services.

\section{References}

Bill, G. (2010). Case Study Research Methods. London: Continuum International Publishing.

Butsch, R. (2009). Introduction: how are media public spheres?. In. R. Butsch (ed.). Media and Public Spheres. New York: Palgrave Macmillan, p. 1-14.

Calhoun, C. ( 1992). Habermas and the Public Sphere. Cambridge: MIT Press.

Dahlgren, P. (1991). Introduction. In. P. Dahlgren \& C. Sparks (ed.). Communication and Citizenship. New York: Routledge, p. 1-26.

Fraser, N. (1990). Rethinking the public sphere: a contribution to the critique of actually existing democracy. Social Text 25(26), 56-88.

Ginsburg, F., Abu-Lughod, L., \& Larkin, B. (2002). Media Worlds: Anthropology

on New Terrain. California: University of California Press.

Habermas, J. (1989). The Structural Transformation of the Public Sphere: An Inquiry into a Category of Bourgeois Society. Oxford: Polity.

Hamilton, M., \& Weiss, M. (2005). Children Tell Stories: Teaching and Using Storytelling in the Classroom ( $2^{\text {nd }}$ ed.). New York: Richard C. Owen.

Howley, K. (2009). Understanding Community Media. Los Angeles: Sage Publications. 
Vol. 1, No. $3 \quad$ Youkongpun: The Role of Community-Based Media in Strengthening...

Jankowski, N. (2002). Creating community with media: history, theories andlscientific investigations. In L. Lievrouw \& S. Livingstone (ed.). Handbook of New Media: Social Shaping and Consequences of ICTs. London: Sage Publications, p. 34-49.

Johnson, F., \& Menichelli, K. (2007). What's Going on in Community Media. Washington: BENTON Foundation.

Katz, E. (1977). Can authentic cultures survive new media. Journal of Communication 27(2), 113-121.

Kemmis, S., \& McTaggart, R. (2005). Participatory Action Research: Communicative Action and the Public Sphere. London: Sage Publications.

Koshy, E., Koshy, V., \& Waterman, H. (2011). Action Research in Healthcare. London: Sage Publications.

Kurpius, D., Metzgar, E., \& Rowley, K. (2011). Defining hyperlocal media: Proposing a framework for discussion. New Media \& Society 13(5), 772-787.

Lips, H. (1991). Women, Men and Power. California: Mountain View.

Meadows, M., Forde, S., Ewart, J., \& Foxwell, K. (2007). Through the smokescreen: Community broadcasting audience research in Australia. In. N. Chitty \& S. Rattikalchalakorn (ed.). Alternative Media: Idealism and Pragmatism. Penang: Southbound Sdn. Hhd, p. 65-91.

Reeves, S., Kuper, A., \& Hodges, B. (2008). Qualitative Research Methodologies: Ethnography. Retrieved from http://bmj.co/1Iy1iJb. [Accessed: 3 February 2014]

Rheingold, H. (2000). The Virtual Community: Homesteading on the Electronic Frontier. Cambridge: MIT Press.

Schensul, S., Schensul, J., \& LeCompte, M. (1999). Essential Ethnographic Methods: Observations, Interviews, and Questionnaires. Calif: AltaMira Press.

Squires, C. (2002). Rethinking the black public sphere: an alternative vocabulary for multiple public spheres. International Communication Association 12(4), 446468.

Streubert, H., \& Carpenter, D. (2002). Qualitative Research in Nursing: Advancing the Humanistic Imperative ( $3^{\text {rd }}$ ed.). Philadelphia: Lippincott Williams \& Wilkins.

Tacchi, J., Foth, M., \& Hearn, G. (2009). Action research practices and media for development. International Journal of Education and Development using Information and Communication Technology 5(2), 32-48.

Tacchi, J., Slater, D., \& Hearn G. (2003). Ethnographic Action Research: A User Handbook Developed to Innovate and Research ICT Applications for Poverty Eradication. New Delhi: United Nations Educational, Scientific and Cultural Organization Regional Bureau for Communication and Information UNESCO.

The Chanthaboon Riverside Community Development Committee (2012). The Riverside Community Photo Collection. Retrieved from www.rimnam.chantha boon.net. [Accessed: 8 December 2012]

Wellmanee, S. (2008). Preliminary study of community radio of Thailand. Retrieved from http://bit.ly/1JDU1WL. [Accessed: 14 October 2014] 